\title{
Structural Equation Modelling of Household Long-Distance Flexible Travel Behavior
}

\author{
Jianjun Zhang ${ }^{1,2}$, Feng Wang ${ }^{1,3}$, Chunfu Shao ${ }^{1 *}$, Xueyu Mi $^{1,4}$ \\ ${ }^{1}$ MOE Key Laboratory for Urban Transportation Complex Systems Theory and Technology, Beijing Jiaotong University, \\ Beijing 100044, China \\ ${ }^{2}$ Urban Space and Transportation Research Center, Jiangsu Zhongshe Group Co. Ltd., Wuxi 214000, China \\ ${ }^{3}$ Intelligent Transport Laboratory, Henan Police College, Zhengzhou 450046, China \\ ${ }^{4}$ North China University of Science and Technology, Tangshan 063000, China
}

Corresponding Author Email: cfshao@bjtu.edu.cn

https://doi.org/10.18280/ijsdp.150406

Received: 10 January 2020

Accepted: 17 March 2020

\section{Keywords:}

household as a unit, flexible travel, travel behavior, structural equation model (SEM)

\begin{abstract}
In recent years, more and more households plan to tourist destinations or visit relatives on holidays. Facing the surging demand for household travel, this paper aims to explore the generation mechanism of household long-distance flexible travel on holidays. Firstly, a questionnaire survey on long-distance flexible travel behavior was conducted among middleincome households in first- and second-tier cities. Then, multiple endogenous and exogenous variables were extracted from the survey data. On this basis, a structural equation model (SEM) was established to analyze the influence of individual attributes, economic attributes, and household attributes over the travel attributes and travel intensity of household long-distance flexible travel. The results show that economic attributes had the greatest impact on travel intensity, among all exogenous variables. This means household income promotes the travel intensity, especially travel duration. Besides, household attributes negatively affect travel intensity. In other words, with the growing number of elderlies, children, and employed in the household, the number of travelers in household travel will increase, while the intensity of household travel will decline; the household will prefer to travel by car. The research results provide theoretical supports to the research of household flexible travel behavior, and enable tourist cities to effectively manage and optimize holiday traffic.
\end{abstract}

\section{INTRODUCTION}

Recent years has seen a surging demand for household longdistance flexible travel, such as visiting relatives and friends, tourism, and leisure. The main reasons for the demand surge include the booming economy, growing living standard, skyrocketing car ownership, the maturity of tourism industry, and the implementation of the annual leave system. Against this backdrop, a huge number of flexible travelers pours into the travel destination, causing nonnegligible problems like traffic congestion and traffic risk. To predict the flexible travel demand, it is necessary to explore the mechanism of flexible travel with household as a unit. Based on the predicted demand, the tourist cities could properly guide and manage holiday travels, and make accurate forecasts of daily urban traffic demand.

So far, there is a lack of analysis on the features of household travel and holiday flexible travel. Most studies on travel behavior are based on travel chains and activities, or oriented towards life, focusing on a kind of individuals or a type of travel activities [1-4]. No attention has been paid to how the travel behavior of an individual is restricted by his/her families or even the allocation of household resources.

At present, some scholars have introduced several influencing factors of individual travel behavior to the analysis on travel behavior, namely, individual living environment, household structure, and household role. From the angle of time utilization, Golob [5] studied the relationship between activity plan of family members and the commuting travel chain of residents. Through disaggregate modelling, Srinivasan et al. analyzed the influence of household factors on the tourism and commuting travel of residents [6,7]. Focusing on the household level, Xianyu and Juan [8] investigated the factors affecting the nonwork activities of residents. Seo et al. [9] set up a travel participation model to reveal the effects of household structure and age on the frequency of maintenance and autonomous travel of residents. Based on the travel chain joint selection model, Feng et al. [10] explored how household structure impacts the selection of travel behavior. Drawing on household social network theory, He et al. probed into the influence of household structure and address on residents' travel $[11,12]$. With the aid of structural equation model (SEM), Zhang et al. [13] discussed how the features of household and community affect the flexible travel of residents. Rözer et al. [14] dug into the effects of household structural changes on travel, pointing out that, after the birth of (a) child(ren), the household will attend more social activities (e.g. visiting relatives and friends, entertainment, and leisure), while reducing work-related travels. Chakrabarti et al. [15] summed up the influence of children on household travel mode: In a household with child(ren) under the age of 15 , the parents will shorten their travel duration, and prefer to travel by car.

The previous research of flexible travel demand fails to 
fully reveal the behavioral features [16, 17], and rarely considers household factors in holiday travel. Yang et al. [18] constructed a nested logit model to compare holiday travel and commuting travel in terms of travel mode selection and travel chain. Based on the complexity of travel chain and the behavior of travel mode selection, Wang et al. established an SEM of holiday travel chain under the effects of traffic information, travel cost, and travel duration, identified the features of holiday travel behavior, and discussed the mechanism of energy consumption and carbon emissions in holiday travel [19-21]. Zhang et al. [22] built up a nonhomogeneous Poisson point process model, and examined the similarities and differences between the impacts of urban spatial structure on holiday travel behavior and workday travel behavior. Han et al. [23] investigated the impact of travel information on holiday travel behavior.

Household flexible travel refers to the collective travel of all or some household members. It is mainly affected by two factors: time and economy. For a household, every member influences the travel decision of the other members. To a certain extent, the household long-distance flexible travel is constrained by the spare time and economic contribution of each household member. The influence of time and economy on household flexible travel varies with household structures. The single-member households, not affected by other members, are flexible in time and self-sufficient in economy. The conjugal households are relatively free in time and economy, because of the weak influence between members. The core households are constrained in time and economy, owing to the existence of child(ren). The stem households are concerned with economy, due to the sheer number of members, but are relatively flexible in time arrangement. To sum up, long-distance flexible travel needs to take account of all household members, and proceed with household as a unit.
However, there is little report that takes household as a unit to tackle long-distance flexible travel behavior.

Targeting long-distance flexible travel behavior, this paper fully considers how household factors affect the dynamic decision on long-distance flexible travel on holidays. The generation mechanism of long-distance flexible holiday travel with household as a unit was discussed in details under the combined effects of individual attributes, household attributes, and economic attributes.

\section{MODELLING}

The SEM is one of the most popular tools used to theorize the dynamics of travel behavior. By integrating data statistics and causal analysis, the SEM can tolerate the measurement errors in explanatory variables in the original data collected through questionnaire survey. Moreover, this approach can clarify the correlations between multi-dimensional variables, discover the hidden relationships out of these correlations, and explain the measurement errors during the evaluation. With these advantages, the SEM has a strong adaptability to objects (e.g. collective travel of a household) affected by multiple factors.

Hence, this paper relies on the SEM to explore the generation mechanism of long-distance flexible travel with household as a unit. First, a questionnaire survey was performed on long-distance flexible travel behavior with household as a unit. Then, the survey data were classified and analyzed, and used to build up an SEM on how travel intensity and travel attributes are affected by individual attributes, household attributes, and economic attributes. The technical roadmap of this research is shown in Figure 1.

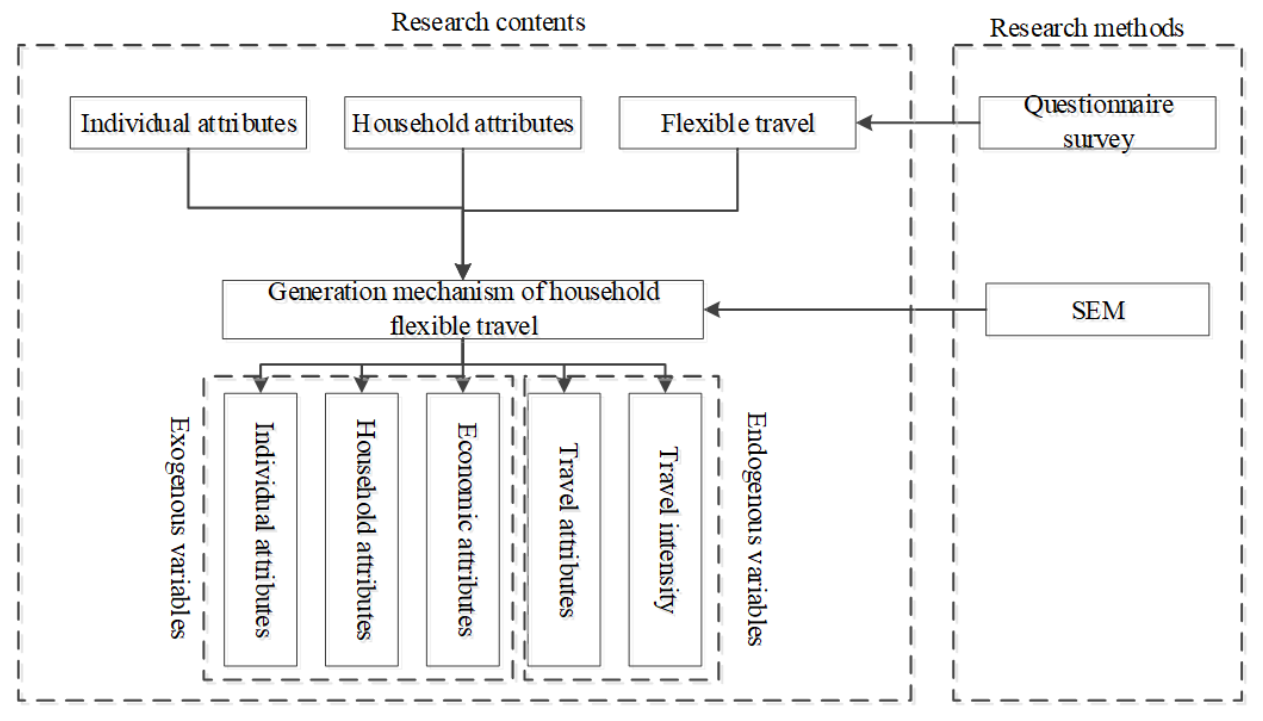

Figure 1. The technical roadmap

\subsection{SEM}

The SEM mainly consists of a structural Eq. (1) and two measurement Eqns. (2) (3) about the relationship between latent and observable variables [24, 25]:

$$
\begin{gathered}
\eta=B \eta+\Gamma \xi+\zeta \\
y=\Lambda_{y} \eta+\varepsilon
\end{gathered}
$$

$$
x=\Lambda_{x} \eta+\delta
$$

where, $\eta$ is the vector of endogenous latent variables; $\xi$ is the vector of exogenous latent variables; $y$ is the vector of endogenous observable variables; $x$ is the vector of exogenous observable variables; $B$ is the coefficient matrix of endogenous latent variables; $\Gamma$ is the coefficient matrix of exogenous latent variables; $\Lambda_{x}$ is the factor loading matrix of exogenous observable variable $\mathrm{x}$ on exogenous latent variable 
$\xi ; \Lambda_{y}$ is the factor loading matrix of endogenous observable variable $x$ on endogenous latent variable $\eta ; \zeta$ is the residual vector of structural equation; $\varepsilon$ is the residual vector of endogenous variables; $\delta$ is the residual vector of exogenous variables.

The SEM parameters were estimated by the following principle: Assuming that the model is correct, the population covariance matrix of the model equals the covariance matrix of all survey samples. Through equalization and iteration, each element in the covariance matrix of the model approaches the corresponding element in the covariance matrix of samples, such as to estimate the parameters of the hypothetical model The common methods of model estimation include maximum likelihood estimation and generalized least squares [26].

\subsection{Data acquisition}

The SEM has certain requirements for the number of variables in the samples. The model analysis cannot proceed stably, unless the number of variables surpasses 100. In general, the number of variables in the samples is controlled above 200. To prevent sample errors from affecting the model results, our questionnaire survey should collect as much data as possible.

The questionnaire survey was carried out from April to October, 2018, covering 244 households in Nanjing, Shanghai, Beijing, and Guangzhou. The main contents of the survey include individual attributes, household attributes, and the information of household long-distance travel. Through the survey, the authors acquired the data on 449 household longdistance flexible travels (Table 1) [27, 28].

The respondents of our survey are mostly middle-income households in first- and second-tier cities. On holidays, these households are very likely to engage in collective tourism and visits to relatives, thanks to relatively high income, stable working hours, rest and vocations, and high car ownership. Therefore, this paper aims to further analyze the generation mechanism of long-distance flexible travel of these households.

Table 1. The survey data

\begin{tabular}{|c|c|}
\hline \multicolumn{2}{|r|}{ Individual attributes } \\
\hline Gender & Male, $48.64 \%$; female, $51.36 \%$ \\
\hline Age & $15-20,5.45 \% ; 21-25,31.52 \% ; 26-30,23.35 \% ; 31-40,25.29 \% ; 41-50,8.95 \% ; 50+, 5.45 \%$ \\
\hline Occupation & $\begin{array}{c}\text { Student, } 30.74 \% \text {; worker, } 4.28 \% \text {; service personnel, } 1.95 \% \text {; office clerk/civil servant, } 47.08 \% \text {; private employee/self- } \\
\text { employed, } 8.17 \% \text {; others, } 7.39 \%\end{array}$ \\
\hline Education & $\begin{array}{c}\text { Graduate from middle school and below, } 5.06 \% \text {; graduate from junior colleges and technical schools, } 13.23 \% \\
\text { bachelor, } 56.03 \% \text {; master, } 23.35 \% \text {; doctor and above, } 2.33 \%\end{array}$ \\
\hline City & First-tier city, $19.07 \%$; second-tier city, $56.42 \%$; third-tier city, $8.95 \%$; other cities, $15.56 \%$ \\
\hline \multicolumn{2}{|r|}{ Household attributes } \\
\hline Household income & $\begin{array}{c}\text { Below RMB 50,000 yuan, } 11.28 \% \text {; RMB 50,000-100,000 yuan, } 21.79 \% \text {; RMB } 100,000-200,000 \text { yuan, } 42.41 \% \text {; RMB } \\
\text { 200,000-400,000 yuan, } 18.29 \% \text {; above RMB 400,000 yuan, } 6.23 \%\end{array}$ \\
\hline Number of elderlies & No elderly above $60,73.77 \%$; one elderly above $60,4.92 \%$; two elderlies above $60,21.31 \%$ \\
\hline Number of children & No minor child, $52.44 \%$; one minor child, $23.17 \%$; two minor children, $23.58 \%$; more than two minor children, $0.81 \%$ \\
\hline Number of employed & Zero, $6.5 \%$; one, $16.67 \%$; two, $59.76 \%$; three, $11.79 \%$; four and more, $5.28 \%$ \\
\hline Housing condition & Own house, $84.44 \%$; rented house, $10.51 \%$; others, $5.06 \%$ \\
\hline House area & $0-100 \mathrm{~m}^{2}, 40.38 \% ; 100-150 \mathrm{~m}^{2}, 51.38 \% ; 150-200 \mathrm{~m}^{2}, 5.96 \%$; above $200 \mathrm{~m}^{2}, 2.29 \%$ \\
\hline Vehicles & $\begin{array}{c}\text { Bike, } 93.97 \% \text {; e-bike/motorcycle, } 89.11 \% \text {; car, } 95.33 \% \text {; e-bike and car, } 87.16 \% \text {; bike and e-bike/motorcycle, } 91.83 \% \text {; } \\
\text { e-bike/motorcycle and car, } 87.55 \% \text {; bike, e-bike/motorcycle, and car, } 86.77 \%\end{array}$ \\
\hline \multicolumn{2}{|r|}{ Household long-distance flexible travels } \\
\hline Travel purpose & Visiting relatives and friends, $58 \%$; tourism, $37 \%$; others, $5 \%$ \\
\hline Number of travelers & Two, $37 \%$; three, $32 \%$; four, $25 \%$; more than four, $6 \%$ \\
\hline Travel distance & Prefectural, $27 \%$; provincial, $35 \%$; domestic, $35 \%$; international, $3 \%$ \\
\hline Travel duration & $2-3 \mathrm{~d}, 57 \% ; 4-7 \mathrm{~d}, 30 \% ; 1-2$ weeks, $10 \%$; more than 2 weeks, $3 \%$ \\
\hline Travel mode & Car, $35 \%$; long-distance bus, $11 \%$; train, $33 \%$; plane, $19 \%$; ferry and others, $2 \%$ \\
\hline
\end{tabular}

Table 2. The rotated factor loading matrix of the nine principal components

\begin{tabular}{cccccccccc}
\hline Principal components & $\boldsymbol{P C 1}$ & $\boldsymbol{P C 2}$ & $\boldsymbol{P C 3}$ & $\boldsymbol{P C 4}$ & $\boldsymbol{P C 5}$ & $\boldsymbol{P C 6}$ & $\boldsymbol{P C 7}$ & $\boldsymbol{P C \boldsymbol { 8 }}$ & $\boldsymbol{P C} \boldsymbol{9}$ \\
\hline Travel duration & .850 & -.004 & -.070 & .024 & -.043 & -.018 & .121 & -.034 & -.049 \\
Travel distance & .820 & -.023 & .074 & -.059 & .023 & .136 & -.133 & .167 & .028 \\
Age & -.025 & .787 & .046 & -.012 & -.212 & .103 & -.079 & .033 & .057 \\
Education & .068 & -.770 & .121 & .021 & -.020 & .276 & -.127 & .039 & .092 \\
Occupation & .029 & .756 & .245 & .088 & -.036 & .281 & -.014 & .007 & .085 \\
Number of children & .002 & .103 & .800 & .216 & .040 & -.138 & .245 & .152 & .124 \\
Number of elderlies & -.016 & .110 & -.227 & .900 & -.041 & -.054 & .039 & .061 & .015 \\
Number of employed & .017 & -.078 & .415 & .825 & .159 & -.074 & .074 & -.025 & .031 \\
Number of cars & -.020 & -.063 & .215 & .150 & .572 & -.464 & .204 & .087 & -.050 \\
House area & .024 & -.107 & .168 & .020 & -.008 & -.792 & -.015 & -.088 & .014 \\
Household income & .216 & -.091 & .277 & -.075 & -.066 & .644 & -.016 & -.105 & .022 \\
Number of travelers & .109 & .003 & .107 & .055 & .162 & -.048 & .857 & -.068 & .053 \\
Travel mode & -.538 & .105 & .059 & -.030 & -.254 & .163 & .479 & -.224 & -.089 \\
Travel purpose & .117 & .011 & .008 & .009 & .033 & .041 & -.093 & .906 & -.026 \\
Gender & .012 & .016 & .021 & .013 & -.005 & .000 & .025 & -.025 & .974 \\
\hline
\end{tabular}




\subsection{Variable selection}

The variables of the survey data were subjected to dimensionality reduction, using the factor analysis function of SPSS. Several composite variables, which are not intercorrelated, were extracted from the 15 original variables about individual attributes, household attributes, and household long-distance travels. The extracted variables cover most of the information in the original variables.

Through the principal component analysis (PCA), the top nine principal components extracted, with a cumulative variance percentage of $81 \%$. The rotated factor loading matrix of the nine principal components is presented in Table 2 above.

As shown in Table 2, PC1 synthesizes the data of travel duration and travel distance, and was named as travel intensity. PC2 integrates age, education, and occupation, while PC9 explains gender; the two principal components were combined into individual attributes. PC3 and PC4 summarizes the number of elderlies, children and employed, and were collectively defined as household attributes. PC5 and PC6 reflects the number of cars, house area, and household income, and were collectively called economic attributes. PC7 and PC8 provide the number of travelers, travel mode, and travel purpose, and were referred to as travel attributes.
To sum up, the dimensions of the 15 variables about household flexible travel were reduced through the PCA, and divided into five classes of attributes: travel intensity, individual attributes, household attributes, economic attributes, and travel attributes. Among them, individual attributes, household attributes, and economic attributes were treated as the exogenous latent variables of the SEM, while travel attributes and travel intensity were taken as the endogenous latent variables of the model. These variables are defined and explained in Table 3.

This research extends the previous studies on factors like household structure, age of household members, and level of household motorization [5-7]. The household factors were assumed to affect household long-distance flexible travel, and the paths between these factors were hypothesized as follows:

$\mathrm{H} 1$ : The exogenous latent variables have an influence on the endogenous latent variables;

$\mathrm{H} 2$ : The exogenous latent variables have an influence on each other;

H3: The travel attributes have an influence on travel intensity.

On this basis, an SEM (Figure 2) was initialized to clarify the correlations between household factors and household long-distance flexible travel.

Table 3. The definition of variables in the SEM

\begin{tabular}{|c|c|c|}
\hline $\begin{array}{l}\text { Exogenous latent } \\
\text { variables }\end{array}$ & $\begin{array}{l}\text { Exogenous observable } \\
\text { variables }\end{array}$ & Signs and values \\
\hline \multirow{4}{*}{ Individual attributes } & Age & $x_{I}($ male $=0 ;$ female $=1)$ \\
\hline & Gender & $x_{2}$ (unit: age) \\
\hline & Occupation & $\begin{array}{c}x_{3}(\text { student }=1 ; \text { worker }=2 ; \text { service personnel }=3 ; \text { office clerk } / \text { civil } \\
\text { servant }=4 ; \text { private employee } / \text { self-employed }=5 ; \text { others }=6)\end{array}$ \\
\hline & Education & $\begin{array}{c}x_{4}(\text { graduate from middle school and below }=1 \text {; graduate from junior } \\
\text { colleges and technical schools }=2 ; \text { bachelor }=3 \text {; master }=4 \text {; doctor and } \\
\text { above }=5)\end{array}$ \\
\hline \multirow{3}{*}{ Household attributes } & Number of children & $x_{5}$ (unit: each) \\
\hline & Number of elderlies & $x_{6}$ (unit: each) \\
\hline & Number of employed & $x_{7}$ (unit: each) \\
\hline \multirow{3}{*}{ Economic attributes } & Number of cars & $x_{8}($ unit: each) \\
\hline & House area & $\begin{array}{c}x_{9} \text { (no own house }=0 \text {; own house area }<50 \mathrm{~m}^{2}=1 \text {; own house area: } 50 \sim 100 \\
m^{2}=2 \text {; own house area: } 100 \sim 150 \mathrm{~m}^{2}=3 \text {; own house area }>150 \mathrm{~m}^{2}=4 \text { ) }\end{array}$ \\
\hline & Household income & $\begin{array}{c}x_{10}(<\mathrm{RMB} 50,000 \text { yuan=1; RMB 50,000-100,000 yuan=2; RMB } \\
100,000-200,000 \text { yuan=3; RMB } 200,000-400,000 \text { yuan=4; }>\text { RMB } \\
\text { 400,000 yuan }=5)\end{array}$ \\
\hline $\begin{array}{l}\text { Endogenous latent } \\
\text { variables }\end{array}$ & $\begin{array}{l}\text { Endogenous observable } \\
\text { variables }\end{array}$ & Signs and values \\
\hline \multirow{3}{*}{ Travel attributes } & Number of travelers & $y_{I}($ unit: each) \\
\hline & Travel purpose & $y_{2}($ visiting relatives and friends $=1 ;$ tourism $=2 ;$ others $=3)$ \\
\hline & Travel mode & $y_{3}($ car $=1 ;$ long-distance bus $=2 ;$ train $=3 ;$ plane $=4$; others $=5)$ \\
\hline \multirow{2}{*}{ Travel intensity } & Travel distance & $y_{4}($ prefectural $=1 ;$ provincial $=2 ;$ domestic $=3 ;$ international $=4)$ \\
\hline & Travel duration & $y_{5}(2-3 \mathrm{~d}=1 ; 4-7 \mathrm{~d}=2 ; 1-2$ weeks $=3 ;$ more than 2 weeks $=4)$ \\
\hline
\end{tabular}

\section{EMPIRICAL ANALYSIS}

\subsection{Estimation of model parameters}

The structure of the initial SEM was adjusted through fitness and significance tests on Amos 21.0. Then, the model parameters were estimated by the maximum likelihood method.

The weight coefficient of each path between variables is presented in Figure 3.

\subsection{Results analysis}

3.2.1 Economic attributes significantly promote travel intensity

As shown in Figure 3, economic attributes had the greatest impact on travel intensity, among all exogenous variables. The weight coefficient for the path between economic attributes and travel intensity was 0.44 . Besides, the impact is positive, i.e. the higher the household income, the longer the duration and distance of household travels for tourism and visiting relatives. 


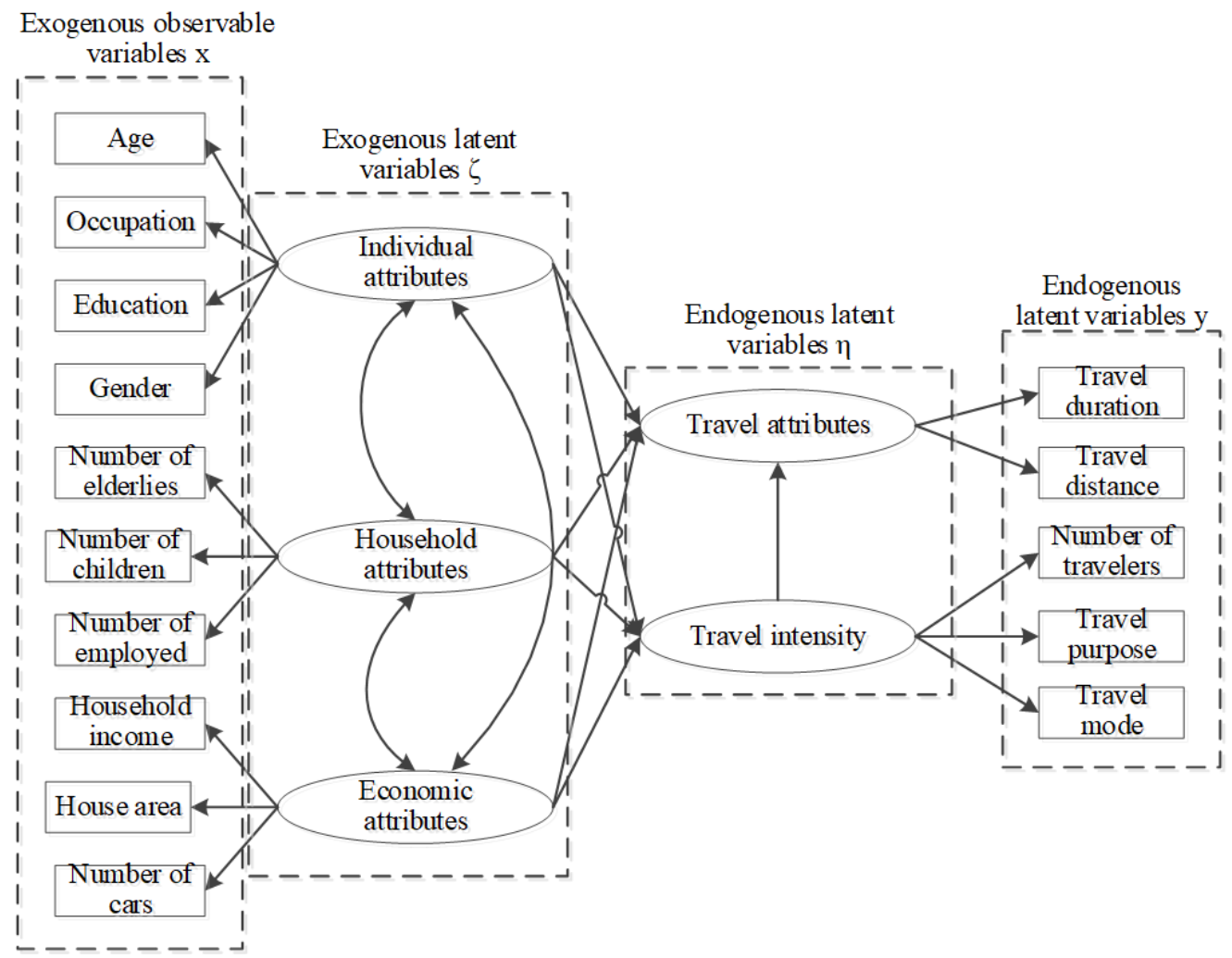

Figure 2. The initial SEM of household long-distance flexible travel

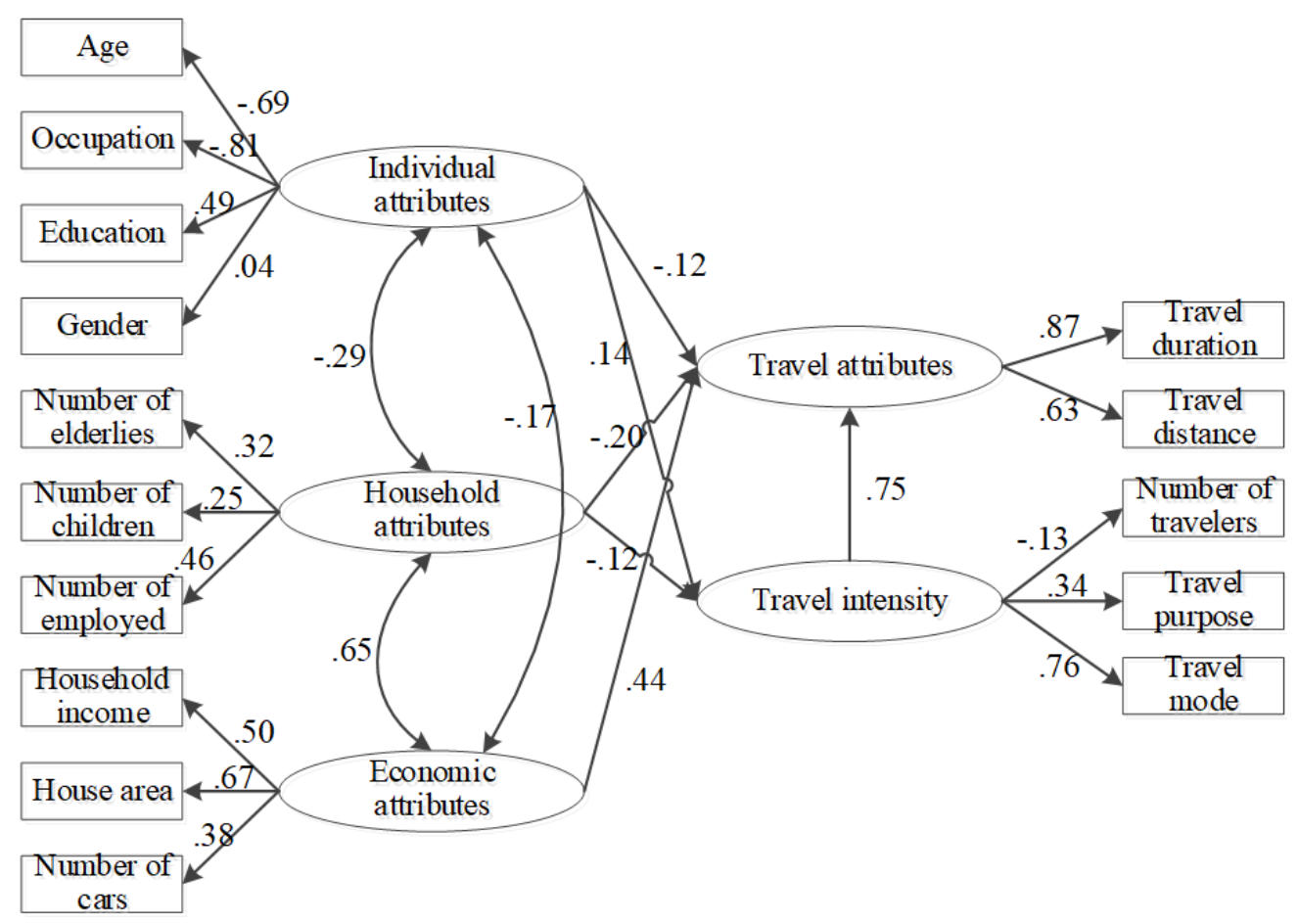

Figure 3. The SEM for household long-distance flexible travel

As a latent variable, economic attributes contain the aftertax annual household income, house area, and the number of cars.

Among them, house area and the number of cars are desirable metrics of household fixed assets, while annual income is a good yardstick of household current assets. The loadings of the three variables were $0.50,0.67$, and 0.38 , respectively. With the largest loading, the house area exerts the most significant impact on travel intensity, especially travel duration.
3.2.2 Household attributes slightly suppress travel intensity

Household attributes both directly affect travel intensity, and indirectly affect the latter via the travel attributes. Thus, the total effect of household attributes on travel intensity can be expressed as:

$$
\begin{gathered}
\text { Total effect }=\text { Directeffect }+ \text { Indirecteffect }= \\
-0.2+(-0.12 \times 0.75)=-0.29 .
\end{gathered}
$$

The results show that household attributes have a negative 
effect on travel intensity (-0.29), indicating that the duration and distance of household long-distance flexible travel will decrease, with the growth in the number of elderlies, children, and employed in the household.

Meanwhile, household attributes also negatively affect the travel mode $(-0.12 \times 0.76)$, that is, a household with many elderlies and children prefers to travel by car.

Besides, household attributes have a negative impact on travel purpose $(-0.12 \times 0.34)$, that is, a household with many elderlies and children will travel at a low frequency.

In addition, household attributes have a positive effect on the number of travelers $(-0.12 \times(-0.13))$, that is, the number of travelers increases with the number of household members; this conclusion is obviously logical.

3.2.3 Individual attributes have a limited impact on travel intensity

Individual attributes affect travel intensity both directly and indirectly. The total effect of individual attributes on travel intensity can be expressed as:

$$
\begin{gathered}
\text { Total effcet }=\text { Directeffect }+ \text { Indirecteffect }= \\
-0.12+(0.14 \times 0.75)=-0.015
\end{gathered}
$$

The results show that the total effect of individual attributes on travel intensity was -0.015 , which is not significant. This means the attributes of an individual member have a limited impact on the collective travel of the entire household.

Of course, the impact on travel intensity varied with individual attributes: gender has little effect on travel intensity, while age and occupation have a certain positive effect on the latter; elderly members are less restricted by work, and tend to travel for longer time over long distance to visit relatives or travel destinations. Besides, education has a certain negative effect on travel intensity; the greater the number of welleducated members, the more restrictions on the duration and distance of household travel.

Furthermore, individual attributes exert certain positive effects on travel mode $(0.14 \times 0.76)$ and travel purpose $(0.14 \times 0.34)$. This means, if a household has many young students, the household will decide to travel flexibly by plane and train to visit relatives and friends.

In summary, the exogenous variables can be ranked as economic attributes (0.44), household attributes $(-0.29)$, and individual attributes $(-0.015)$, in descending order of the total effect on travel intensity.

\subsection{Model evaluation}

The fitness indices of our model (Table 4) all fell in the recommended intervals, that is, our model has good fitness.

Table 4. Interpretation of endogenous variables in structural equation models

\begin{tabular}{ccc}
\hline Evaluation indices & $\begin{array}{c}\text { Index } \\
\text { values }\end{array}$ & $\begin{array}{c}\text { Recommended } \\
\text { intervals [29] }\end{array}$ \\
\hline $\begin{array}{c}\text { Minimum Chi-square/degree } \\
\text { of freedom (Cmin } / \mathrm{DF})\end{array}$ & 2.135 & $1-3$ \\
$\quad \begin{array}{c}\text { Goodness of fit (GFI) } \\
\text { Adjusted goodness of fit } \\
\quad \text { (AGFI) }\end{array}$ & 0.955 & $>0.9$ \\
$\begin{array}{c}\text { Root mean square residual } \\
\text { (RMR) }\end{array}$ & 0.925 & $>0.9$ \\
$\begin{array}{c}\text { Root mean square error of } \\
\text { approximation (RMSEA) }\end{array}$ & 0.406 & $<0.5$ \\
\hline
\end{tabular}

\section{CONCLUSIONS}

In this paper, a questionnaire survey is conducted on the long-distance flexible travel behavior of urban households. Based on the survey data, endogenous and exogenous variables were identified, and integrated into an SEM. The established model was used to analyze how individual attributes, economic attributes, and household attributes affect the travel attributes and travel intensity of household longdistance flexible travel.

The results show that economic attributes are the key factor affecting the travel intensity: the higher the household income, the more intense the household travel. Household attributes negatively affect travel intensity and travel attributes. In other words, with the growing number of elderlies, children, and employed in the household, the number of travelers in household travel will increase, while the frequency and intensity of household travel will decline; the household will prefer to travel by car. Individual attributes have insignificant effect on travel intensity.

The future research will expand the survey scope to lowincome households in first- and second-tier cities, collect even more survey samples, and include other household factors into the analysis.

\section{ACKNOWLEDGEMENTS}

This work was supported by the Fundamental Research Funds for the Central Universities of Ministry of Education of China (Research on theory and method of collaborative planning, design and operation of urban transportation system), the project number was 2017JBZ106.

\section{REFERENCES}

[1] Lee, J. (2016). Impact of neighborhood walkability on trip generation and trip chaining: Case of los angeles. Journal of Urban Planning and Development-Asce, 142(3):

5015013 https://doi.org/10.1061/(ASCE)UP.1943-5444.0000312

[2] Ding, Y., Lu, H., Sun, X. (2016). Impact of improved accessibility on shopping activity: Person-based measure. Journal of Urban Planning and Development-Asce, 142(3): $\quad 4016006$. https://doi.org/10.1061/(ASCE)UP.1943-5444.0000325

[3] Manoj, M., Verma, A. (2017). A structural equation model based analysis of non-workers' activity-travel behaviour from a city of a developing country. Transportation, 44(2): 241-269. https://doi.org/10.1007/S11116-015-9636-8

[4] Feng, J. (2017). The influence of built environment on travel behavior of the elderly in urban China. Transportation Research Part D-Transport and Environment, 52: 619-633. https://doi.org/10.1016/J.TRD.2016.11.003

[5] Golob, T.F. (2000). A simultaneous model of household activity participation and trip chain generation. Transportation Research Part B-Methodological, 34(5): 355-376. https://doi.org/10.1016/S0191-2615(99)000284

[6] Srinivasan, S., Ferreira, J. (2002). Travel behavior at the household level: Understanding linkages with residential 
choice. Transportation Research Part D: Transport and Environment, 7(3): 225-242. https://doi.org/10.1016/S1361-9209(01)00021-9

[7] Srinivasan, S., Bhat, C. R. (2005). Modeling household interactions in daily in-home and out-of-home maintenance activity participation. Transportation, 32(5): 523-544. https://doi.org/10.1007/S11116-005-5329-Z

[8] Xianyu, J.C., Juan, Z.C. (2011). Generation and organization of household non-work activity stops. Journal of Transportation Systems Engineering and Information Technology, 11(4): 128-132. https://doi.org/10.3969/j.issn.1009-6744.2011.04.019

[9] Seo, S.E., Ohmori, N., Harata, N. (2013). Effects of household structure and accessibility on travel. Transportation, 40(4): 847-865. https://doi.org/10.1007/S11116-013-9468-3

[10] Feng, J., Dijst, M., Wissink, B., Prillwitz, J. (2013). The impacts of household structure on the travel behaviour of seniors and young parents in China. Journal of Transport Geography, 30: 117-126. https://doi.org/10.1016/J.JTRANGEO.2013.03.008

[11] He, B.H., Liu, Y., He, Y., Li, Z.H. (2016). Theories and confirmed model of household's activity-travel behavior based on social network. Journal of Transportation Systems Engineering and Information Technology, 16(3): 235-240. https://doi.org/10.3969/j.issn.10096744.2016 .03 .035

[12] He, B.H., He, Y., Wang, Y.J., Zhang, X. (2017). Selection mechanisms of residents' daily activity-travel behavior with housing mobility. Journal of Transportation Systems Engineering and Information Technology, 17(3): 19-25 https://doi.org/10.16097/j.cnki.1009-6744.2017.03.004

[13] Zhang, P., Deng, N.J., Jiang, Y.Y. (2017). Structural equations analysis on non-work trip of residents' activity and travel behavior. Journal of Tongji University (Natural Science), 45(9): 1311-1318. https://doi.org/10.11908/j.issn.0253-374x.2017.09.009

[14] Rözer, J.J., Poortman, A.R., Mollenhorst, G. (2017). The timing of parenthood and its effect on social contact and support. Demographic Research, 36(62): 1889-1916. https://doi.org/10.4054/DEMRES.2017.36.62

[15] Chakrabarti, S., Joh, K. (2019). The effect of parenthood on travel behavior: Evidence from the California Household Travel Survey. Transportation Research Part A-Policy and Practice, 120: 101-115. https://doi.org/10.1016/J.TRA.2018.12.022

[16] Wang, J., Tan, C., Liu, Z. (2018). Parking management efficiency analysis through various charge schemes for day-long commuting considering elastic travel demand. Journal of Advanced Transportation, 2018: 1580287. https://doi.org/10.1155/2018/1580287

[17] Li, W., Li, Y., Ban, X., Deng, H., Shu, H., Xie, D. (2018). Exploring the relationships between the non-work trip frequency and accessibility based on mobile phone data. Transportation Research Record, 2672(42): 91-102. https://doi.org/10.1177/0361198118774170

[18] Yang, L., Shen, Q., Li, Z. (2016). Comparing travel mode and trip chain choices between holidays and weekdays. Transportation Research Part A-Policy and Practice, 91: 273-285. https://doi.org/10.1016/J.TRA.2016.07.001

[19] Wang, B., Shao, C., Ji, X. (2017). Dynamic analysis of holiday travel behaviour with integrated multimodal travel information usage: A life-oriented approach. Transportation Research Part A-Policy and Practice, 104: 255-280. https://doi.org/10.1016/J.TRA.2017.03.013

[20] Wang, B., Shao, C., Ji, X. (2017). Influencing mechanism analysis of holiday activity-travel patterns on transportation energy consumption and emissions in $\begin{array}{lll}\text { China. } & \text { Energies, } & \text { 10(7): }\end{array}$ https://doi.org/10.3390/EN10070897

[21] Wang, B., Timmermans, H.J.P., Rasouli, S., Shao, C. (2018). Dynamic effects of long-term and mid-term mobility decisions on holiday travel behavior choice: A Bayesian decision network approach. Proceedings of the 15th International Conference on Travel Behavior Research, Santa Barbara, United States.

[22] Zhang, S., Liu, X., Tang, J., Cheng, S., Wang, Y. (2019). Urban spatial structure and travel patterns: Analysis of workday and holiday travel using inhomogeneous Poisson point process models. Computers, Environment and Urban Systems, 73: 68-84. https://doi.org/10.1016/J.COMPENVURBSYS.2018.08. 005

[23] Han, Y., Zhang, T., Wang, M. (2020). Holiday travel behavior analysis and empirical study with Integrated Travel Reservation Information usage. Transportation Research Part A-Policy and Practice, 134: 130-151. https://doi.org/10.1016/J.TRA.2020.02.005

[24] Konduri, K.C., Astroza, S., Sana, B., Pendyala, R.M., Jara-Diaz, S.R. (2011). Joint analysis of time use and consumer expenditure data: Examination of two approaches to deriving values of time. Transportation Research Record, 2231(2231): 53-60. https://doi.org/10.3141/2231-07

[25] Golob, T.F. (2003). Structural equation modeling for travel behavior research. Transportation Research Part B-Methodological, 37(1): 1-25. https://doi.org/10.1016/S0191-2615(01)00046-7

[26] Zhang, W., Susilo, Y.O., Termida, N.A. (2016). Investigating the interactions between travellers' familiar areas and their multi-day activity locations. Journal of Transport Geography, 53: 61-73. https://doi.org/10.1016/J.JTRANGEO.2016.04.012

[27] Gao, G., Wang, Z., Liu, X., Li, Q., Wang, W., Zhang, J. (2019). Travel behavior analysis using 2016 Qingdao's household traffic surveys and Baidu electric map API data. Journal of Advanced Transportation, 2019: 3067291. https://doi.org/10.1155/2019/6383097

[28] Jiao, J., Bischak, C., Hyden, S. (2020). The impact of shared mobility on trip generation behavior in the US: Findings from the 2017 National Household Travel Survey. Travel Behaviour and Society, 19: 1-7. https://doi.org/10.1016/J.TBS.2019.11.001

[29] Wu, M.L. (2009). Structural Equation Model: Operation and Application of AMOS. Chongqing University Press. 